\title{
Thermodynamic Equilibrium Analysis of Methanol Conversion to Hydrocarbons Using Cantera Methodology
}

\author{
Duminda A. Gunawardena and Sandun D. Fernando \\ Biological and Agricultural Engineering Department, Texas A\&M University, College Station, TX 77843, USA \\ Correspondence should be addressed to Sandun D. Fernando, sfernando@tamu.edu
}

Received 29 June 2011; Revised 23 November 2011; Accepted 11 December 2011

Academic Editor: Krzysztof J. Ptasinski

Copyright ( 2012 D. A. Gunawardena and S. D. Fernando. This is an open access article distributed under the Creative Commons Attribution License, which permits unrestricted use, distribution, and reproduction in any medium, provided the original work is properly cited.

\begin{abstract}
Reactions associated with removal of oxygen from oxygenates (deoxygenation) are an important aspect of hydrocarbon fuels production process from biorenewable substrates. Here we report the equilibrium composition of methanol-to-hydrocarbon system by minimizing the total Gibbs energy of the system using Cantera methodology. The system was treated as a mixture of 14 components which had $\mathrm{CH}_{3} \mathrm{OH}, \mathrm{C}_{6} \mathrm{H}_{6}, \mathrm{C}_{7} \mathrm{H}_{8}, \mathrm{C}_{8} \mathrm{H}_{10}$ (ethyl benzene), $\mathrm{C}_{8} \mathrm{H}_{10}$ (xylenes), $\mathrm{C}_{2} \mathrm{H}_{4}, \mathrm{C}_{2} \mathrm{H}_{6}, \mathrm{C}_{3} \mathrm{H}_{6}, \mathrm{CH}_{4}, \mathrm{H}_{2} \mathrm{O}, \mathrm{C}, \mathrm{CO}_{2}$, $\mathrm{CO}, \mathrm{H}_{2}$. The carbon in the equilibrium mixture was used as a measure of coke formation which causes deactivation of catalysts that are used in aromatization reaction(s). Equilibrium compositions of each species were analyzed for temperatures ranging from 300 to $1380 \mathrm{~K}$ and pressure at $0-15 \mathrm{~atm}$ gauge. It was observed that when the temperature increases the mole fractions of benzene, toluene, ethylbenzene, and xylene pass through a maximum around $1020 \mathrm{~K}$. At $300 \mathrm{~K}$ the most abundant species in the system were $\mathrm{CH}_{4}, \mathrm{CO}_{2}$, and $\mathrm{H}_{2} \mathrm{O}$ with mole fractions $50 \%, 16.67 \%$, and $33.33 \%$, respectively. Similarly at high temperature (1380 K), the most abundant species in the system were $\mathrm{H}_{2}$ and $\mathrm{CO}$ with mole fractions $64.5 \%$ and $32.6 \%$ respectively. The pressure in the system shows a significant impact on the composition of species.
\end{abstract}

\section{Introduction}

Methanol is the simplest alcohol which has a tremendous importance as an industrial feedstock $[1,2]$. As a fuel, methanol does not have high enough specific heat value to compete with gasoline and therefore its not attractive as a substitute but as a motor fuel additive it is said to be improving the fuel quality. The prospect of methanol being used as raw material for fuel processing actually started with the accidental discovery by Chang and Silvestry in the early 70s [3]. With the use of newly discovered ZSM-5 it was found that methanol can be transformed to gasoline grade products. Methanol conversion process in the industry has branched into two paths, namely, methanol to olefins (MTO) and methanol to gasoline (MTG). Even though MTG got the global attention as an alternative route to produce fuel, it was unable to make the process economically viable $[4,5]$. To make the process economical the process parameters has to be optimized. Catalyst upgrading to make deoxygenation reaction more selective toward gasoline products such as benzene, toluene, ethylbenzene, and xylene (BTEX) is one such approach $[6,7]$. Another approach is to alter the reaction conditions such as temperature, pressure, and residence time to augment the desired product spectrum $[6,8]$. For this purpose, understanding the energetics of the MTG reaction pathway by thermodynamic analysis is also an important step.

The reaction pathway of MTG process is not yet completely resolved. However, from the available information in the literature, it is clear that it involves a series of reactions [9]. How the first C-C bond formation occurs is still under debate [10-12]. The widely accepted model so far is based on the hydrocarbon pool method where it is described as a catalytic scaffold with organic molecules adsorbed on to the zeolite structure $[13,14]$.

As given in Figure 1, MTG process takes place in a series of steps where formation of dimethyl ether is said to be the first step. Olefinic products produced at the secondary stage is significant for the MTO process while at tertiary stage is gasoline grade products are obtained. The products of MTG 


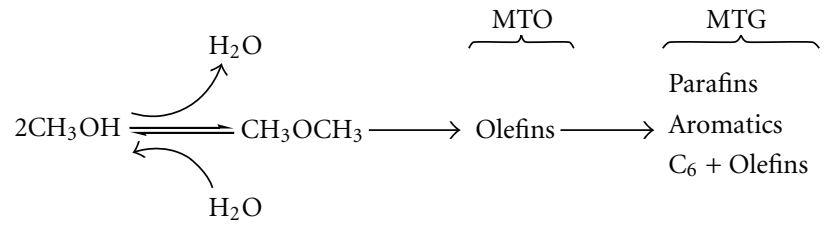

FIgURE 1: Reaction pathway of MTO and MTG processes as proposed in the literature [15].

process consists of a mixture of paraffins, aromatics, and olefins, and for the thermodynamic system, are treated as equilibrium products in this analysis.

\section{Thermodynamic Equilibrium Analysis}

If the stoichiometric equation of methanol conversion to aromatic hydrocarbons is known, the thermodynamic equilibrium analysis can easily be performed using the equilibrium constant. However, when the reaction stoichiometry is not known, the nonstoichiometric method should be used. Equilibrium composition for nonstichiometric systems can be determined by different methods such as energy minimization technique, kinetic/dynamic model, or by neural network technique. Since our system involves temperature and pressure as variables, it is much convenient to select Gibbs free energy minimization technique. In this study, a code written in Python (an open source programming language) to run the Cantera software library was used to analyze the equilibrium composition of the model mixture. Cantera is an object oriented software tool developed by a team from California Institute of Technology for solving chemical kinetics, thermodynamics, and transport processes [16]. Equilibrium composition was determined by Gibbs energy minimization by the Villars-Cruise-Smith algorithm [17]. Thermodynamic data for the species were calculated using the nine-coefficient NASA polynomial [18]. All the coefficients for the polynomial were obtained from Burcats online database [19].

\section{Results and Discussion}

The outcome of the optimization routine is the mole fraction of each of the fourteen compounds in the mixture at each pressure and temperature. Since it is a gas phase system, the partial pressure of each component is proportional to mole fraction and results are analyzed in those terms. As expected, the system with the fourteen components reaches equilibrium at different temperatures and pressures.

The key input to the model was the standard formation enthalpies of different species considered. Table 1 gives the formation enthalpies as obtained from [20].

3.1. Methanol Conversion to Aromatics. According to the thermodynamic analysis, equilibrium aromatics yield at different temperatures is extremely low. Figure 2(a) depicts that the BTEX mole fraction trend in the equilibrium mixture passes through a maximum around $1100 \mathrm{~K}$. The mole fraction of BTEX clearly increases as pressure increases.
TABLE 1: Standard formation enthalpies of the species considered in the system.

\begin{tabular}{cc}
\hline Compound name & $\Delta H_{f}^{o}(\mathrm{~kJ} / \mathrm{kmol})$ \\
\hline $\mathrm{CH}_{3} \mathrm{OH}$ & -205 \\
$\mathrm{C}_{6} \mathrm{H}_{6}$ & 82.8 \\
$\mathrm{C}_{7} \mathrm{H}_{8}$ & 50.1 \\
$\mathrm{C}_{8} \mathrm{H}_{10}$ (ethyl benzene) & 49.0 \\
$\mathrm{C}_{8} \mathrm{H}_{10}$ (xylenes) & 17.9 \\
$\mathrm{C}_{2} \mathrm{H}_{4}$ & 52.47 \\
$\mathrm{C}_{2} \mathrm{H}_{6}$ & -83.8 \\
$\mathrm{C}_{3} \mathrm{H}_{6}$ & 20.41 \\
$\mathrm{CH}_{4}$ & -74.87 \\
$\mathrm{H}_{2} \mathrm{O}$ & -241.83 \\
$\mathrm{C}$ & 0.0 \\
$\mathrm{CO}_{2}$ & -393.52 \\
$\mathrm{CO}$ & -110.53 \\
$\mathrm{H}_{2}$ & 0.0 \\
\hline
\end{tabular}

The reaction model considered in this study resembles a thermochemical conversion of methanol at different pressures. It is interesting to note that all the aromatics considered in the model initiated formation around $850 \mathrm{~K}$ and peaked approximately around $1110 \mathrm{~K}$. The formation started to disappear beyond $1300 \mathrm{~K}$.

This analysis suggests that to maximize gasoline fraction aromatic products formation, the reactions should be carried out at a narrow temperature regime. This temperature window broadens as pressure increases but is quite narrow at lower pressures. It appears that the best reaction temperature for gasoline range aromatics formation is around $800-850^{\circ} \mathrm{C}$.

In order to better approximate experimental BTX yields the model was forced to reach equilibrium with eleven hydrocarbon products such as $\mathrm{CH}_{3} \mathrm{OH}, \mathrm{C}_{6} \mathrm{H}_{6}, \mathrm{C}_{7} \mathrm{H}_{8}, \mathrm{C}_{8} \mathrm{H}_{10}$ (ethyl benzene), $\mathrm{C}_{8} \mathrm{H}_{10}$ (xylenes), $\mathrm{C}_{2} \mathrm{H}_{4}, \mathrm{C}_{2} \mathrm{H}_{6}, \mathrm{C}_{3} \mathrm{H}_{6}, \mathrm{CH}_{4}$, $\mathrm{H}_{2} \mathrm{O}, \mathrm{H}_{2}$ neglecting thermodynamically more stable species such as $\mathrm{CO}_{2}, \mathrm{CO}$, and $\mathrm{C}$. This forced equilibrium conditions resulted in changing the aromatic mole fraction in the system significantly as shown in Figure 2(b). According to this analysis, the highest total aromatic mole percentage of 9.41\% was observed at 0 psi and $1380 \mathrm{~K}$. Thermodynamics favor benzene formation in both methods in the aromatic fraction and the highest yield is reported at 0 psi and $1380 \mathrm{~K}$.

3.2. Methanol Conversion to Paraffins. Methane, ethane, and propane are the alkanes considered in this model. It is quite 

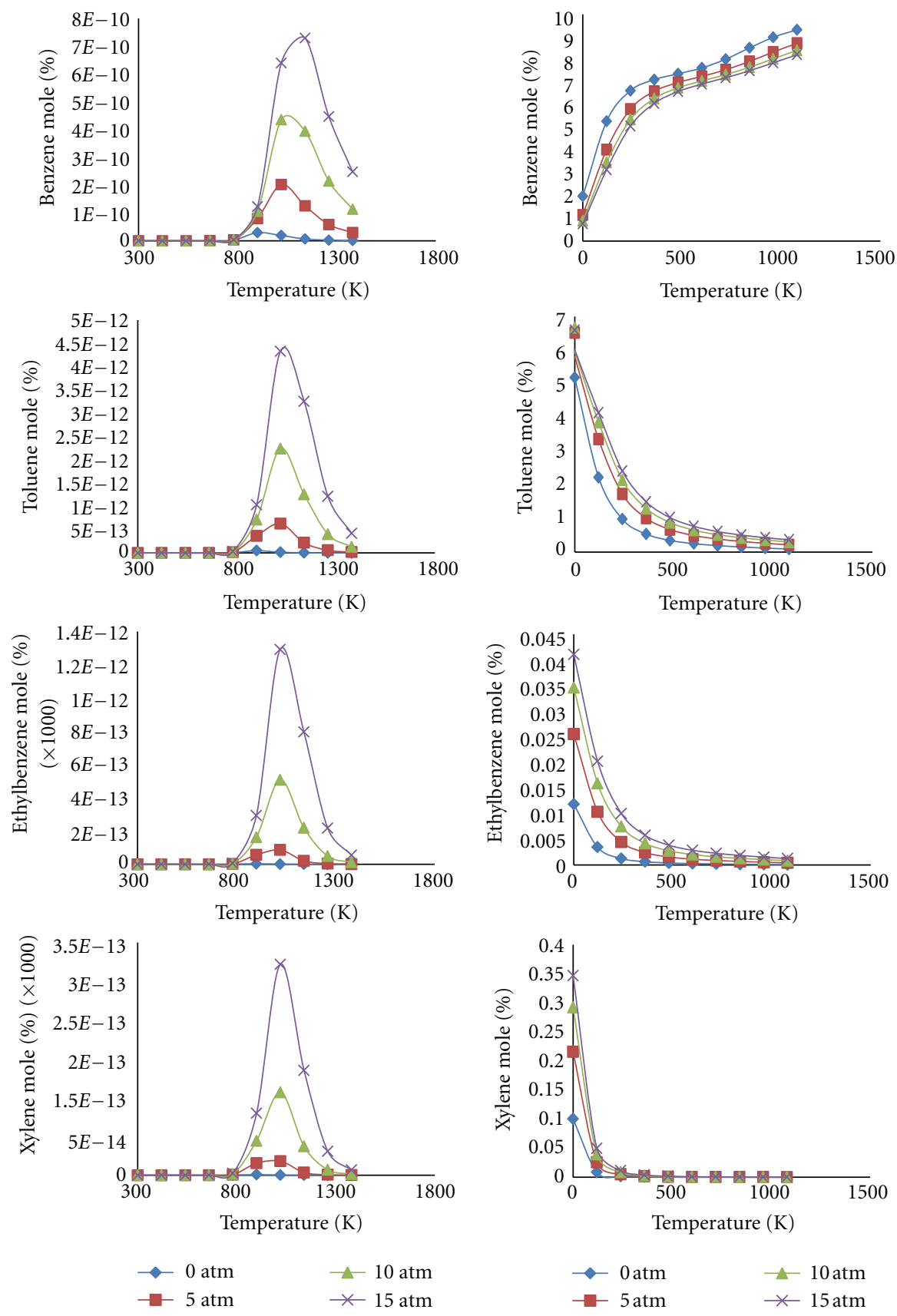

(a)

(b)

FIGURE 2: (a) Equilibrium composition of gasoline-range aromatic hydrocarbons in the fourteen-component model. (b) The equilibrium composition of aromatics after the system was forced to equilibrate with eleven species removing $\mathrm{CO}_{2}, \mathrm{CO}$, and $\mathrm{C}$.

interesting that methane is the most abundant alkane in the equilibrium mixture at $300 \mathrm{~K}$ under both models that were tested.

Molar faction of ethane is relatively low, but, shows an interesting behavior with respect to temperature and pressure (Figure 3). Increasing pressure increases the mole fraction of ethane and with increasing temperature, the trends is to pass through a maximum around $900 \mathrm{~K}-$ $1120 \mathrm{~K}$. According to the unrestricted model, propane mole percentage in the equilibrium mixture is very low-including the forced equilibrium model. The analysis indicates that methane is the only alkane, that is, thermodynamically favorable.

3.3. Methanol Conversion to Olefins. In this thermodynamic model, we have considered ethylene which has been reported to be present when methanol is catalytically processed [6]. It is widely believed that ethylene is one of the preliminary 

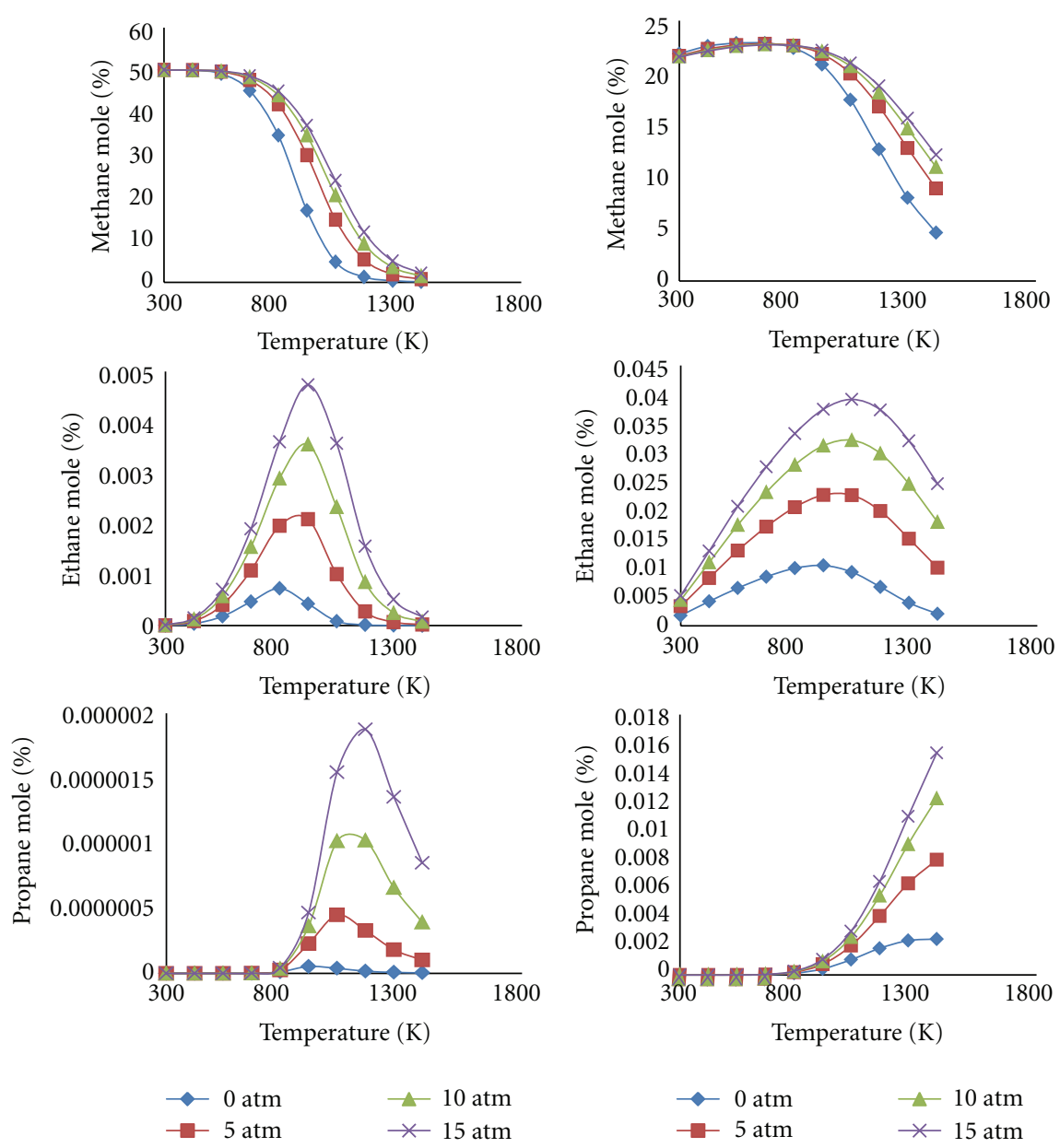

(a)

(b)

FIgURE 3: Equilibrium mole fractions of paraffins (a) with thermodynamically stable species considered in the model, (b) when $\mathrm{CO}_{2}$, $\mathrm{CO}$, and $\mathrm{C}$ dropped from the model.

products when methanol is converted in the presence of catalyst such as ZSM-5. However, according to Figure 4(a), it is clear that in the equilibrium mixture, the mole percentage of ethylene is quite low but under the forced equilibrium ethylene shows a significant presence than ethane and propane. It is clear that under both models, the increase of temperature clearly favored formation of ethylene.

3.4. Formation of Solid Carbon and Syngas. Carbon that is produced in the reaction is commonly attributed as a cause for catalyst deactivation. It can be seen from Figure 5(a) that carbon formation varies significantly as the temperature increases but the equilibrium mole percents are extremely low. Accordingly, the effect of pressure on carbon formation is not significant. It should be noted that in practice, the coke formation can happen not only as a result of direct carbon deposition but also by deposition of larger molecular weight carbonaceous compounds on active sites of the catalyst.

Under unrestricted equilibrium conditions, two reaction schemes can be proposed for the system. At low temperatures $(300-500 \mathrm{~K})$ the most abundant species in the system are methane, water, and carbon dioxide. All the other species in the model can be neglected since these are present in extremely low concentrations at these temperatures. This reaction is depicted in stoichiometric form in (1). The heat of reaction which amounts to $-281.79 \mathrm{~kJ} / \mathrm{mol}$ indicates that it is highly exothermic and the products methane, water, and carbon dioxide are the most stable at low temperatures. Similarly, at higher temperatures the most abundant and the most stable species are carbon monoxide and hydrogen. Hydrogen is present in the highest concentrations at temperatures $>1000 \mathrm{~K}$ in the mixture which amounts to $66.1 \%$ in the unrestricted equilibrium model. The products (formed at high temperature environment) can be represented in a stoichiometric form as shown in (2):

$4 \mathrm{CH}_{3} \mathrm{OH} \longrightarrow 3 \mathrm{CH}_{4}+2 \mathrm{H}_{2} \mathrm{O}+\mathrm{CO}_{2}, \quad \Delta H_{f}=-281.79 \mathrm{~kJ} / \mathrm{mol}$,

$$
\mathrm{CH}_{3} \mathrm{OH} \longrightarrow \mathrm{CO}+2 \mathrm{H}_{2}, \quad \Delta H_{f}=94.47 \mathrm{~kJ} / \mathrm{mol} .
$$

The system with fourteen species attains thermodynamic equilibrium at different temperatures and pressures. At 


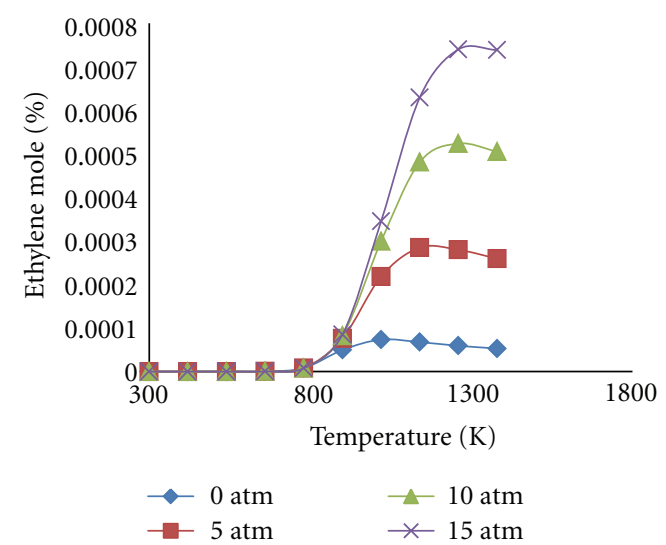

(a)

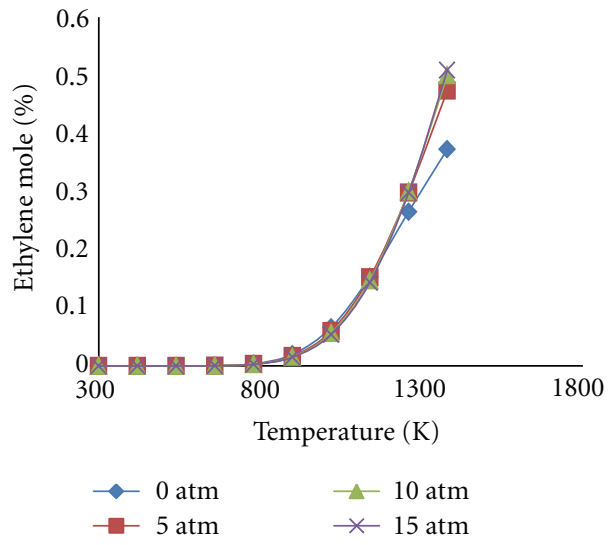

(b)

FIGURE 4: Variation of carbon mole fraction with respect to temperature at different pressures.

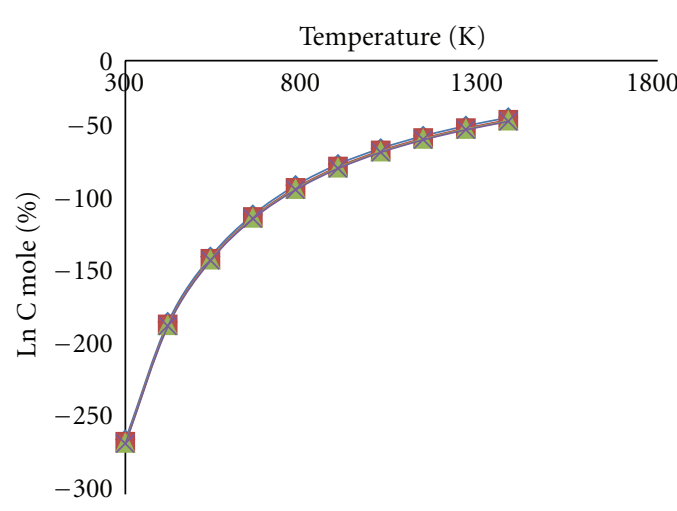

(a)

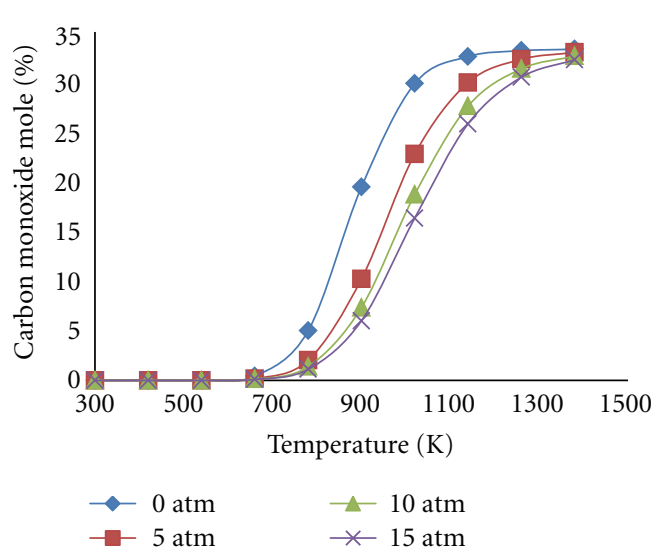

(c)

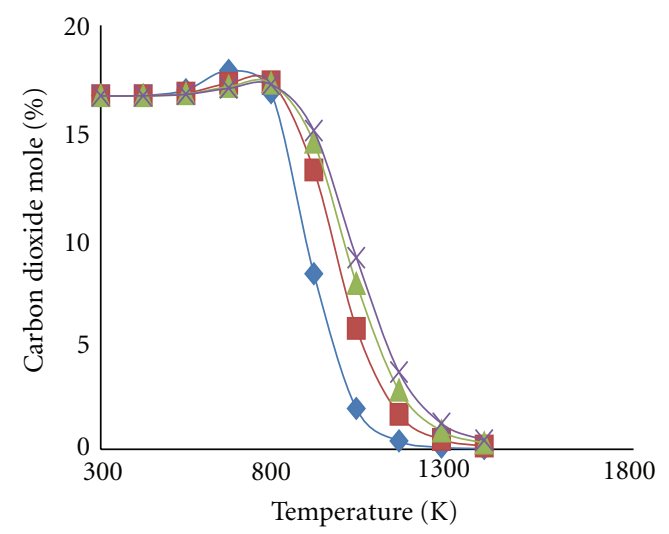

(b)

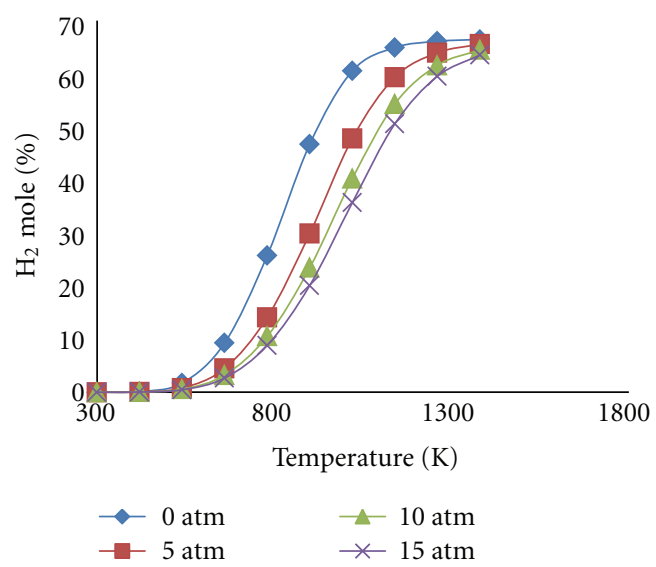

(d)

Figure 5: Variation of (a) carbon, (b) carbon dioxide, (c) carbon monoxide, (d) hydrogen, mole fraction with respect to temperature at different pressures.

equilibrium, the overall $\Delta G$ of the mixture is a measure of how stable the reaction is at respective reaction conditions. According to Figure 6, the Gibbs free energy of the system stays in negative region implying that the reaction is spontaneous. As the temperature increases the negative value of $\Delta G$ increases and reaches a minimum around $780 \mathrm{~K}$.

For this system under equilibrium, an equilibrium constant can be calculated using (3). According to Figure 7, the system has a large equilibrium constant. A reaction with 


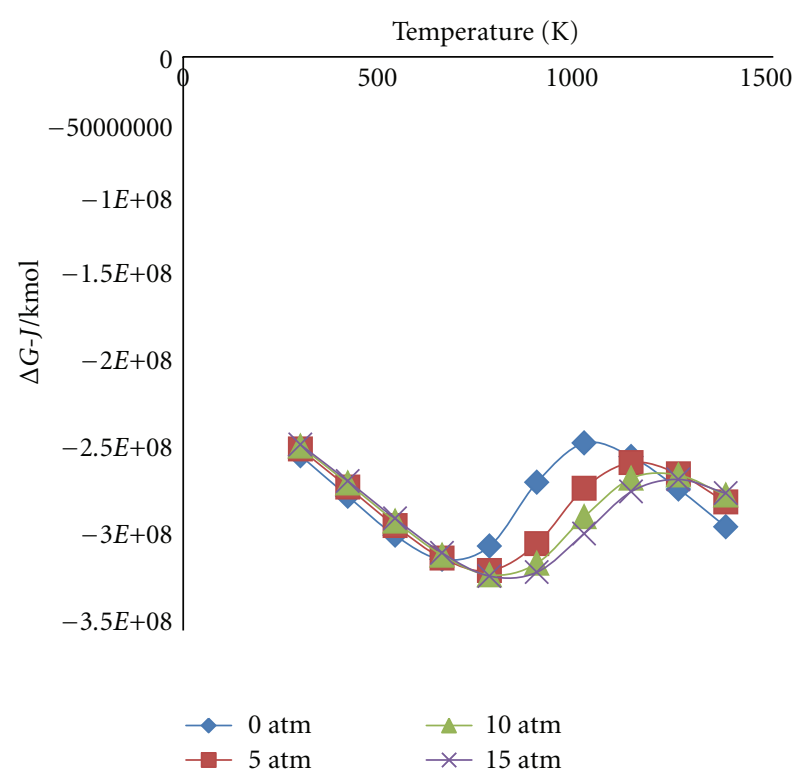

FIGURE 6: Variation of the total Gibbs free energy of the reaction $\left(\Delta G_{r x}^{o}\right)$ with respect to temperature at different pressures.

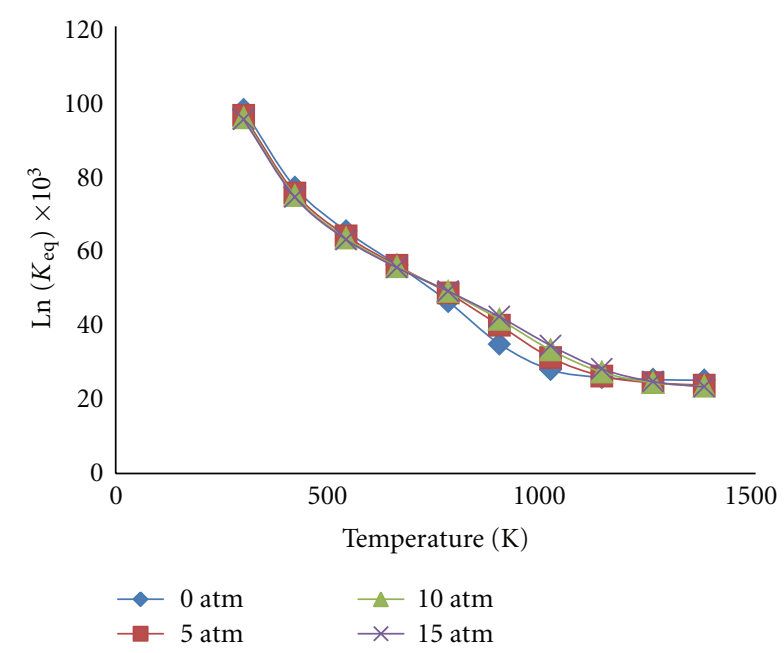

FIGURE 7: Variation of the equilibrium constant of the system with respect to temperature at different pressures.

a large equilibrium constant can take a long time to reach the equilibrium depending on the kinetics of the reaction. As the temperature increases the equilibrium constant reduces exponentially:

$$
K_{a}=\exp \left(\frac{-\Delta G}{R T}\right)
$$

The overall analysis suggests that when this mixture is left to equilibrate at the temperature and pressure conditions specified, the tendency of the system is to favor formation of low molecular weight compounds (such as $\mathrm{CH}_{3}, \mathrm{CO}, \mathrm{CO}_{2}$, $\mathrm{H}_{2}$, and $\mathrm{H}_{2} \mathrm{O}$ ). Although in a liquid fuel production point of view, we anticipate obtaining high yields of hydrocarbons, this analysis suggests that the equilibrium mole percent of BETX can reach up to $9.41 \%$. This observation could be reinforced by the fact that $\Delta H_{f}$ for BTEX are all positive, the system tends to favor formation of more stable compounds with more negative $\Delta H_{f}$ values [21]. Accordingly, it is clear that at higher temperatures, in the absence of a catalyst, the tendency of methanol is to produce a Syngas containing primarily $\mathrm{CO}$ and $\mathrm{H}_{2}$. However, literature suggests that the dynamics of the reaction changes in the presence of a catalyst such as ZSM-5. It has been shown that in the presence of a catalyst under analogous conditions, significant amounts of BTEX (with ethylene and xylenes having the highest selectivities) are produced [6]. The inference of this analysis is that, in the presence of a catalyst, simultaneous formation of all considered molecules does not occur from methanol; rather, independent reactions that comprise of only a few selected intermediate products may occur. However, with sufficient time, these energetically favorable intermediates will break down to more stable low molecular weight compounds.

\section{Conclusions}

Two models were tested to understand the behavior of aromatics, alkanes, and alkenes production when methanol is thermochemically deoxygenated. Under the forced equilibrium conditions it shows that the aromatic mole percentage is $9.41 \%$. At low temperature the most abundant stable species were methane, carbon dioxide, and water, while hydrogen and carbon monoxide were the most dominant stable species at higher temperatures. Methane was the most abundant species at low temperature with a mole fraction of $50 \%$. At high temperature the most abundant species was hydrogen with mole fraction $66.1 \%$. The system under equilibrium produces negligible amounts of elemental carbon. The negative values of the free energy $(\Delta G)$ of the system indicate that the reaction is spontaneous for the entire range of temperatures pressures that were analyzed. Further, the analysis indicates that increasing temperature would increase the negative value of free energy making the system stable. The overall equilibrium constant of the system drops exponentially with increasing temperature.

\section{Acknowledgment}

This paper is based upon work supported by the National Science Foundation under Grant no. CBET 0965772.

\section{References}

[1] X. Yin, D. Y. C. Leung, J. Chang, J. Wang, Y. Fu, and C. Wu, "Characteristics of the synthesis of methanol using biomassderived syngas," Energy \& Fuels, vol. 19, no. 1, pp. 305-310, 2005.

[2] P. Reubroycharoen, T. Yamagami, T. Vitidsant, Y. Yoneyama, M. Ito, and N. Tsubaki, "Continuous lowtemperature methanol synthesis from syngas using alcohol promoters," Energy \& Fuels, vol. 17, no. 4, pp. 817-821, 2003. 
[3] C. D. Chang and A. J. Silvestri, "The conversion of methanol and other O-compounds to hydrocarbons over zeolite catalysts," Journal of Catalysis, vol. 47, no. 2, pp. 249-259, 1977.

[4] M. W. Anderson and J. Klinowski, "Solid state NMR studies of the shape-selective catalytic conversion of Methanol into gasoline on Zeolite ZSM-5," Journal of the American Chemical Society, vol. 112, no. 1, pp. 10-16, 1990.

[5] B. C. Gates, Catalytic Chemistry, The Wiley Series in Chemical Engineering, Wiley, 1991.

[6] R. Barthos, T. Bánsági, T. Süli Zakar, and F. Solymosi, "Aromatization of methanol and methylation of benzene over $\mathrm{Mo}_{2} \mathrm{C} / \mathrm{ZSM}-5$ catalyst," Journal of Catalysis, vol. 247, no. 2, pp. 368-378, 2007.

[7] D. Freeman, R. P. K. Wells, and G. J. Hutchings, "Conversion of methanol to hydrocarbons over $\mathrm{Ga}_{2} \mathrm{O}_{3} / \mathrm{H}-\mathrm{ZSM}-5$ and $\mathrm{Ga}_{2} \mathrm{O}_{3} / \mathrm{WO}_{3}$ catalysts," Journal of Catalysis, vol. 205, no. 2, pp. 358-365, 2002.

[8] Ø. Mikkelsen and S. Kolboe, "The conversion of methanol to hydrocarbons over zeolite H-beta," Microporous and Mesoporous Materials, vol. 29, no. 1-2, pp. 173-184, 1999.

[9] D. M. McCann, D. Lesthaeghe, P. W. Kletnieks et al., "A complete catalytic cycle for supramolecular methanol-to-olefins conversion by linking theory with experiment," Angewandte Chemie, vol. 47, no. 28, pp. 5179-5182, 2008.

[10] S. R. Blaszkowski and R. A. Van Santen, "Theoretical study of C-C bond formation in the methanol-to- gasoline process," Journal of the American Chemical Society, vol. 119, no. 21, pp. 5020-5027, 1997.

[11] J. E. Jackson and F. M. Bertsch, "Conversion of methanol to gasoline: a new mechanism for formation of the first carboncarbon bond," Journal of the American Chemical Society, vol. 112, no. 25, pp. 9085-9092, 1990.

[12] S. M. Campbell, X. Z. Jiang, and R. F. Howe, "Methanol to hydrocarbons: spectroscopic studies and the significance of extra-framework aluminium," Microporous and Mesoporous Materials, vol. 29, no. 1-2, pp. 91-108, 1999.

[13] U. Olsbye, M. Bjørgen, S. Svelle, K. P. Lillerud, and S. Kolboe, "Mechanistic insight into the methanol-to-hydrocarbons reaction," Catalysis Today, vol. 106, no. 1-4, pp. 108-111, 2005.

[14] I. M. Dahl and S. Kolboe, "On the reaction mechanism for propene formation in the MTO reaction over SAPO-34," Catalysis Letters, vol. 20, no. 3-4, pp. 329-336, 1993.

[15] D. A. Gunawardena and S. D. Fernando, "Deoxygenation of methanol over ZSM-5 in a high pressure catalytic pyroprobe," Chemical Engineering and Technology, vol. 34, no. 2, pp. 173178, 2011.

[16] D. Goodwin, "Cantera: an object-oriented software toolkit for chemical kinetics, thermodynamics, and transport processes," http://code.google.com/p/cantera/.

[17] M. Baratieri, P. Baggio, L. Fiori, and M. Grigiante, "Biomass as an energy source: thermodynamic constraints on the performance of the conversion process," Bioresource Technology, vol. 99, no. 15, pp. 7063-7073, 2008.

[18] A. Burcat and B. Ruscic, "Third millenium ideal gas and condensed phase thermochemical database for combustion with update from active thermochemical tables," Tech. Rep., Argonne National Laboratory, 2005.

[19] A. Burcat and B. Ruscic, New NASA Thermodynamic Polynomials Database With Active Thermochemical Tables updates, ANL 05/20 TAE 960, 2010, ftp://ftp.technion.ac.il/ pub/supported/aetdd/ thermodynamics.

[20] A. F. Kazakov, NIST/TRC Web Thermo Tables (WTT) Professional Edition, Thermodynamics Research Center, 2010.
[21] S.I. Sandler, Chemical, Biochemical, and Engineering Thermodynamics, John Wiley \& Sons, 2005. 

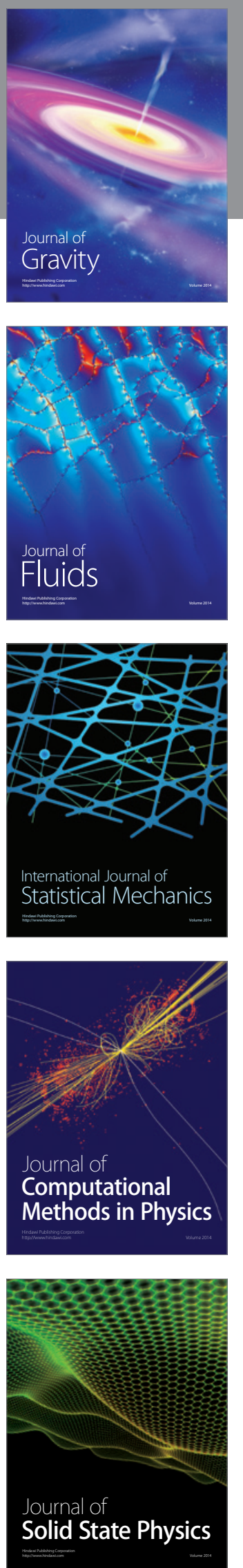

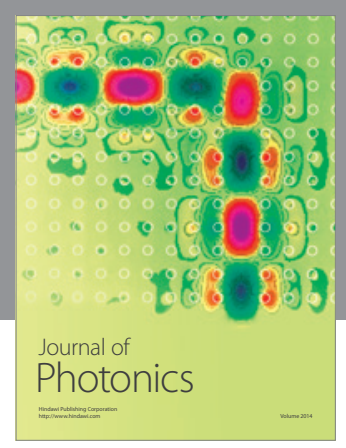

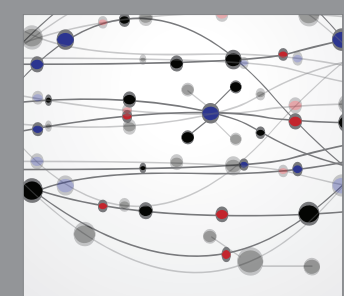

The Scientific World Journal
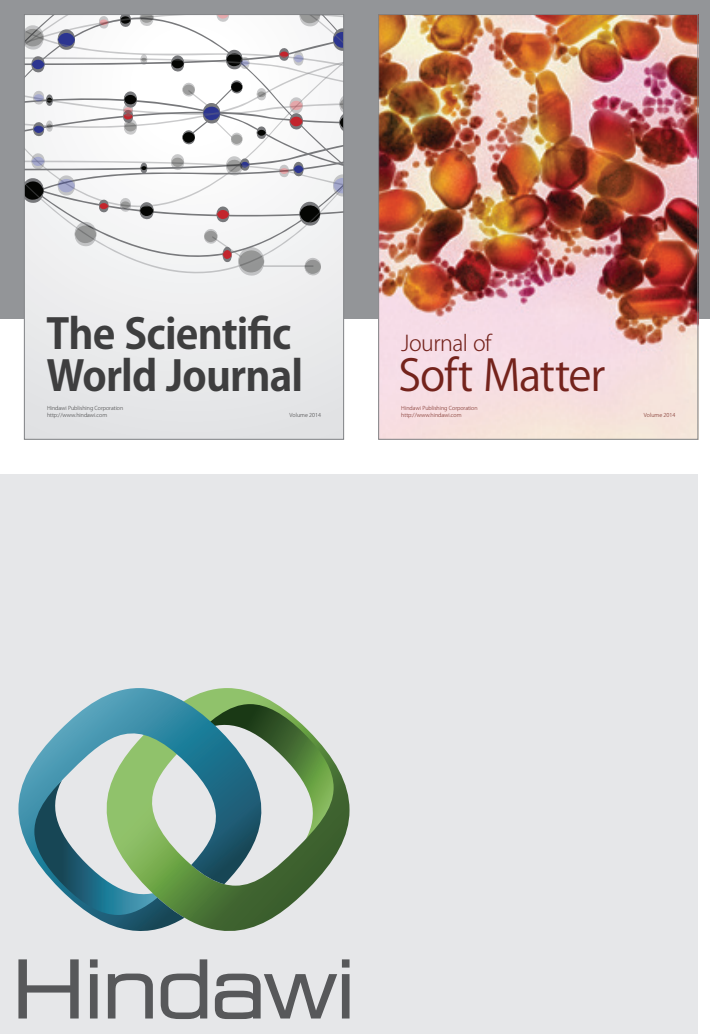

Submit your manuscripts at

http://www.hindawi.com
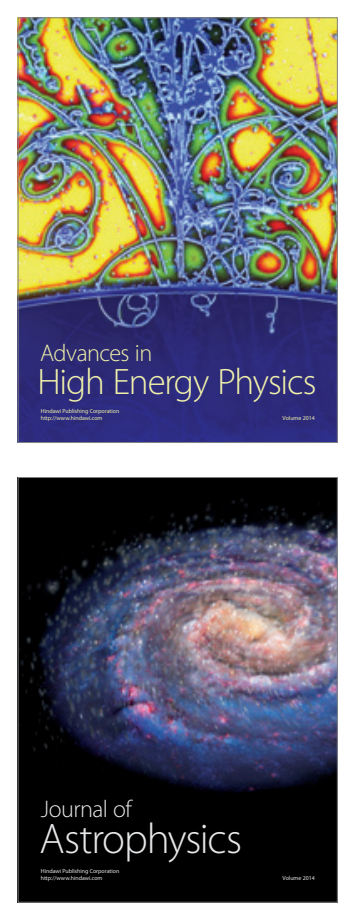
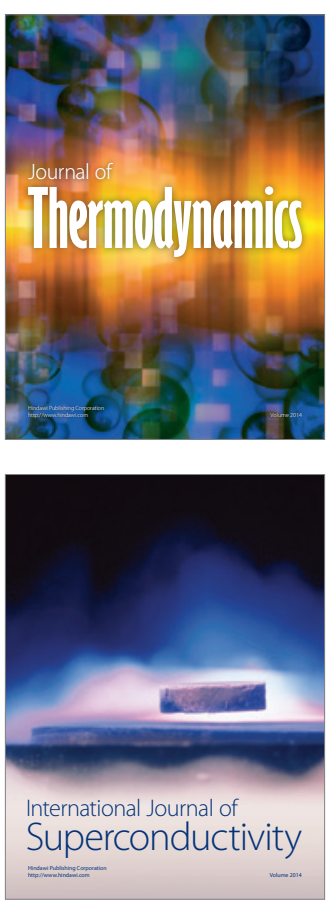
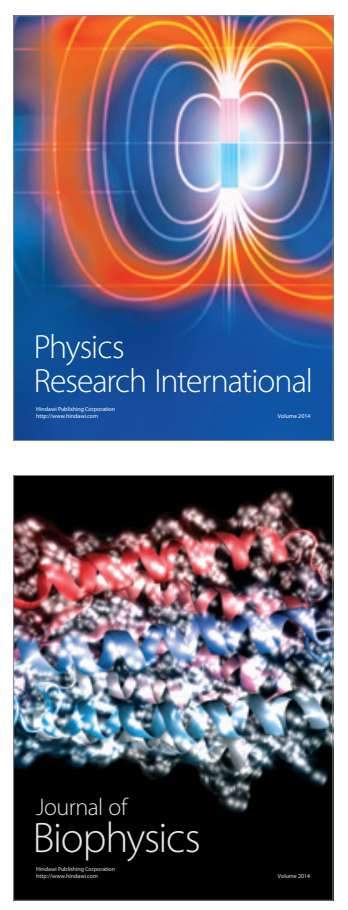
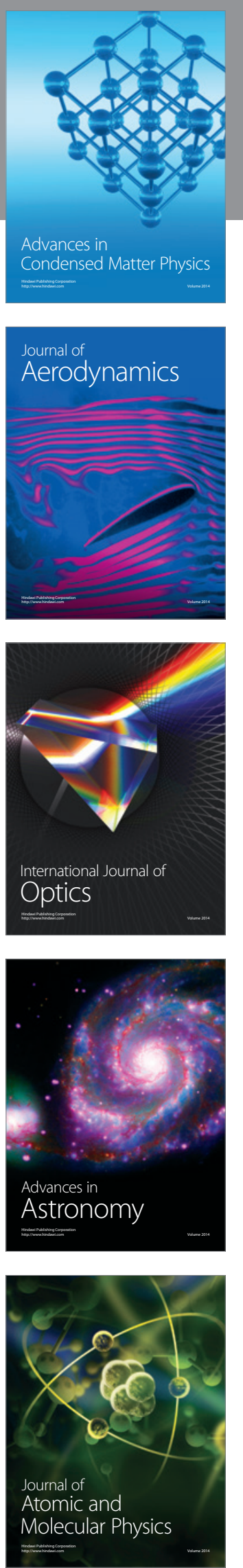